\title{
Building a comprehensive, evidence based tobacco treatment system in managed care
}

In February 1999, professionals from health plans, public health, and academia met in San Diego, California, United States to discuss opportunities and challenges in implementing tobacco control strategies in managed care. Proceedings from this second annual Addressing Tobacco in Managed Care conference comprise this supplement to Tobacco Control. Presenters include managed care plans which have been the early adopters of the Agency for Health Care Policy and Research (AHCPR) (renamed the Agency for Healthcare Research and Quality in December 1999) smoking cessation clinical practice guidelines, ${ }^{1}$ tobacco control leaders advocating change and providing resources, and dedicated researchers testing new practices and interventions in achieving a smoke free population.

To all these innovators, we as patients, payers, and community members thank you for your insights and diligence in pursuing the vision of a comprehensive, evidence based tobacco dependence treatment system in managed care. Through linkages to community based programs and policy efforts, these systems can offer even more powerful and proactive messages and assistance to current and would be smokers. As demonstrated in this issue by Blue Cross and Blue Shield of Minnesota (page i65), Group Health Cooperative of Puget Sound (page i17), Health Partners (page i15), and the Oregon Statewide Tobacco Cessation Project (page i67), managed care is a welcome partner and leader in state and community wide efforts to create healthier communities by reducing smoking prevalence. In return, managed care reaps the economic benefits of one of the most cost effective interventions in medicine..$^{2-4}$

As we approach the four year mark of the availability of the AHCPR guidelines and the upcoming release of its revisions, we face several challenges to achieve fully integrated tobacco treatment systems across managed care. As Henningfield points out (page i8), “ . . . whether or not treatment works, or can contribute to public health when made more accessible, are no longer core questions. The big question is how do we make tobacco dependence treatment even more accessible and acceptable?". Creative ways to raise consumer and purchaser demand must be found. Smokers must be readily identified by health plans through the implementation of low cost, user friendly office systems. Providers must embrace and practise all 4A's (ask, advice, assist, arrange). Time consuming, but critical day-to-day operational issues - such as maintaining key leadership involvement, choosing vendors and tailored materials, and convincing office staff of the importance of adding new systems - must be addressed. Several articles in this issue describe experiences of a specific health plan in managing the ongoing reality of implementing and sustaining a comprehensive tobacco intervention system (pages i18-i48). One of the biggest challenges to those of us in leadership positions is to convey these lessons and insights to every health care system in the country.

Conference proceedings such as these, the annual Addressing Tobacco in Managed Care conference, the Robert Wood Johnson Foundation and the American Association of Health Plans Addressing Tobacco in Managed Care National Technical Assistance Office, and continuing support and efforts by our conference sponsors (the Agency for Health Care Policy and Research, the Centers for Disease Control and Prevention, the National Cancer Institute, and the Robert Wood Johnson Foundation) described in the section on discovering new resources for managed care (pages i71-i75), are intended to help meet this dissemination challenge.

We hope these conference proceedings will provide many suggestions, tools, and encouragement towards a nationwide adoption of accessible, affordable, and acceptable tobacco treatment systems in managed care.

With many thanks to our authors, Simon Chapman, Mary Grace Flaherty, Tracy Orleans, Linda Schuessler, Danielle Skripak Stoffer, and John Weller for Tracy Orleans, Linda Schuessler, Danielle Skripak S
ensuring the timely production of these proceedings.

DIANNE C BARKER Guest Editor

Barker Bi-Coastal Health Consultants

3556 Elm Drive

Calabasas

CA 91302

USA

1 Fiore MC, Bailey WC, Cohen SJ, et al. Smoking cessation. Clinical Practice Guideline No 18. Rockville, Maryland: US Department of Health and Human Services, Public Health Service, Agency for Health Care Policy and Resch April 1996. (AHCPR Publication No 96-0692) < Policy www.text.nlm.nih.gov/ftrs/tocview>.

2 Cromwell J, Bartosch WJ, Fiore MC, et al. Cost-effectiveness of the clinical practice recommendations in the AHCPR guidelines for smoking cessation. FAMA 1997;278:1759-66.

3 Eddy DM. David Eddy ranks the tests. Harvard Health Letter (special suppl). July 1992;10-11.

4 Warner, KE. Cost-effectiveness of nicotine replacement therapy. In: Future directions in nicotine replacement therapy. Chester, UK: Adis International, 1993:37. 